\title{
Behavioral Ecology of Conservation in Traditional Societies
}

Bobbi S. Low

Evolution and Human Behavior Program, and

School of Natural Resources and Environment

University of Michigan

Ann Arbor, MI 48109-1115

electronic mail: bobbi.low@um.cc.umich.edu

fax: 313/936-2195

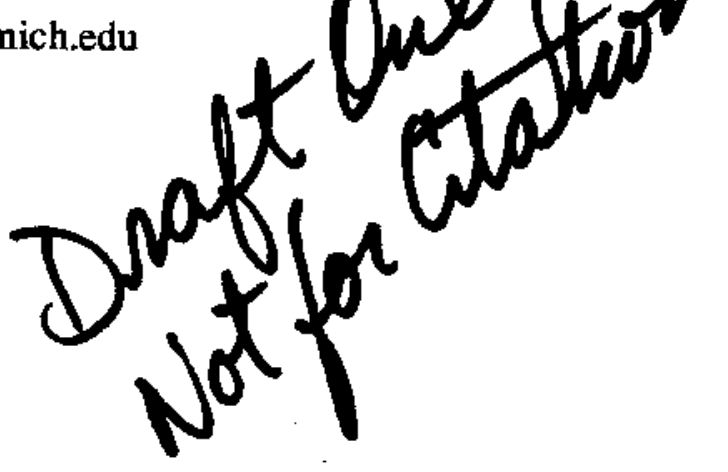




\section{Introduction}

Today, as we face increasingly complex environmental problems, of ever-enlarging scale, we are faced by a dilemma: our ideas about what we should do to solve these problems are based on conventional wisdoms about our conservation ethics, and our willingness to trust and cooperate with others. One "wisdom" is our perception that people in pre-industrial ("traditional") societies, being more directly and immediately dependent on the ecology of the natural systems around them, were more conserving and respectful of those resources (e.g. Bodley 1990) than we. Another is that, perhaps because traditional people typically lived in small groups (often among kin), they were likelier to be willing to sacrifice personal benefit for the good of the group, when conditions demanded it.

We feel we have, in important ways, "lost touch" with ecological constraints as we have developed technological insulation against ecological scarcity and fluctuations - and thus that we may have drifted away from ecological concern and from cooperativeness. Thus, we fmd ourselves thinking that if only we could recapture the reverence and cooperativeness of traditional societies, and expand it, we could solve our problems. These conventional wisdoms generate normative prescriptions: that in addition to more information about the impact of our actions on ecological balances, we need to become more reverent, to move closer to the ideal we hold of traditional peoples' patterns.

The first wisdom is a common problem in biology and anthropology; the biological term is "levels of selection." That is, personal striving for status and resources is widespread, and problems can arise if technologies are efficient, or population densities are high. Wise management of the problem is likely to require some lowering of individual profit, or increase in individual cost, compared to behaviors which will be individually rational. To examine it, we really need to know not only whether a society expressed an ethos of restraint, but whether that ethos was effective - whether societies with ethos of restraint were in fact more conserving of their resources than other societies. Our current strategies of education in conservation reflect our trust in this wisdom, but in fact we have few data on effectiveness.

Competition among individuals over resources is virtually universal; cooperation among individuals (often in precisely the same context of resource competition) is rarer. The form of the resource is important in predicting whether people will cooperate: it matters whether an individual or group can exclude competing individuals. Such resources are "private goods" (Ostrom and Ostrom 1977); examples in biology are territorial defense, or the immediate consumption of small patches of resources, whether the resource constitutes a commons. Commons resources are those for which it is difficult to exclude use by others; they have the peculiar property that the benefit to over-use accrues to the individual, while the costs of over-use is shared among all users (see Oye 
and XX 19XX, on the two sort of commons). Many of our current ecological dilemmas have the properties of commons. Among traditional societies, commons problems are also common (e.g. see Hawkes 1992).

Thus it's of particular interest when we can identify commons that are managed, despite the temptations of individually rational, group-destructive behavior, in a way that is far-sighted and conserving. There are strong suggestions from laboratory gaming experiments that repeated interactions are important in fostering the necessary trust and cooperativeness (e.g. Walker XX 19XX). Did peoples in traditional society cooperate to a greater extent than we do today? Were there conscribed areas (e.g. natal family) of cooperation?

My purpose here is to step back from complex situations, and examine these problems in traditional societies: [1] whether evidence of environmental degradation exists in traditional societies; [2] when (under what ecological conditions) a strong conservation ethic is evidenced in traditional societies; and whether it bears any relationship to degradation; and [3] under what conditions societies attempt to foster the characteristics (e.g. trust) that facilitate cooperation. I seek commonalties which perhaps can then be used in teasing apart more complex examples.

\section{A Behavioral Ecological Approach}

Despite all our cultural complexity, we humans must solve the same ecological problems as all other organisms in order to survive and reproduce. And, however complex the interaction between our genes and the external environment, when family lineages die out, they are replaced by other, competing, lineages. Thus, behavioral ecologists often calculate an unfamiliar sort of self-interest: genetic self interest. Further, despite a certain amount of polemic (e.g., Lewontin et al. 1984), the evidence is accumulating that it is appropriate to apply to humans, at least for the purposes of generating hypotheses, the central paradigm in biology: that humans, like other living organisms, have evolved to maximize their genetic contribution to future generations through producing offspring and assisting non-descendant relatives; that the particular strategies accomplishing such maximization will differ in specifiable ways in different environments; and, just as for other mammals, these strategies will typically differ between the sexes. Humans can, through their extensive elaboration of devices like nepotism and reciprocity, respond in complex and subtle ways; this does not mean that selection is absent.

In the behavioral ecological literature (e.g. see Cronk 1991, Krebs and Davies 1992), two things stand out: [1] genetically selfish behaviors, those which enhance an individuals' genetic representation (through direct reproduction or assistance of relatives), are always favored; and [2] fertility responds to the richness, controllability and predictability of important resources, and to the sources of juvenile mortality. All living things have evolved to acquire and use resources to 
survive and reproduce. The ways they do so are constrained by ecological conditions; the most effective and efficient resource strategies in any particular environment are those that tend to prevail over time. Ceteris paribus, those individuals using efficient strategies leave more offspring in the next generation than their competitors.

In non-human species there is a well-known ecology of reproductive effort, broader than may be obvious. Environments exert selective impact, through differential survivorship and reproduction, on any organism's strategy. The sexes differ: variance in age-specific fertility is greater for males than for females. That is, fewer males than females actually reproduce, although the most fecund males far out-reproduce the most fecund females (Clutton-Brock et al., 1982, 1986; Le Boeuf and Reiter, 1988). Organisms have at their disposal at any moment some amount of calories to spend, and some level of acceptable risk. Individuals that allocate calories and risk optimally (and selective optimality is definable a priori through examination of ecological circumstances) survive and leave more progeny than their competitors.

Over time, the families of optimal strategists come to control more of the available resources and to comprise a greater proportion of the population. Yet unalloyed fertility is seldom the winning strategy (Low 1993XX). The relative success of opposing strategies (producing many offspring versus investment in each offspring) imposes a real constraint (Darwin, 1871; Trivers, 1972; see review by Low et al 1991, Low 1993XX). Reproductive strategies and ecological factors such as resources (richness, controllability, and predictability) and the sources of juvenile mortality (i.e., whether parental effort can enhance survivorship) are clearly correlated.

Thus, genetic conflicts of interest exist: individuals strive to increase their own inclusive fitness (Hamilton 1964, Grafen 1991: 9-13), in a finite world, at the expense of non-related individuals. Many strategies, not only "genetically determined" mechanisms, are available to do so. Genes and environment clearly interact, and no attempt can succeed which either ignores genetic components, or seeks to explain behavior simply as a series of genetically-programmed events. We know that members of families are more alike than strangers, and the wealth of twinsraised-apart studies make it clear than many very subtle traits have strong genetic components. But we also know that intrafamilial correlations of traits such as cognitive ability differ among populations, and there are strong sex-by-generation and ethnic group-by-generation interactions (e.g., DeFries et al. 1982). That is, intrafamilial similarities arise both through genetic and environmental (family environment) influences, and are further modified by external (cultural environmental) factors.

Looking at human behavior across times and places means, of course, that it is important to examine the conditions driving behaviors to be similar, and also those which will drive the behaviors to differ. One major difference between humans and other organisms, of course, is the existence of our particular kind of consciousness, allowing complex social responses to varying 
conditions, frequently through extremely well-developed cultural transmission and technology (cf. Humphrey 1983, Alexander 1990, 1987, Cavalli-Sforza and Feldman 1981, Lumsden and Wilson 1981, Boyd and Richerson 1986, Durham 1991). Humans are also exceptionally longlived, and several generations may overlap. We live sometimes in population densities extraordinary for a vertebrate. We create and accumulate heritable resources, and we extend the period of our parental effort to a degree not known in any other species; in fact, parental investment does not end, even at death (e.g., inheritance rules and wills; see Smith et al. 1987).

Individuals and their genetic lines can obviously prosper through reciprocity or cooperation (Trivers 1971), which can be a highly effective competitive strategy. Particularly when we examine resource strategies, cooperation is centrally important. Humphrey (1983) and Alexander (1971, 1979, 1987) argue that even our powerful human intelligence probably evolved in the context of resource and mate competition. Reciprocity occurs only in long-lived, social species - species in which individuals recognize each other and are likely to interact repeatedly. Organisms in long-lived, social species including humans, are likely to do things which benefit potential reciprocators without immediate profit, because there is some probability that there will be future interactions between/among the individuals (indirect reciprocity).

If individuals interact only rarely or occasionally, indirect reciprocity is extremely vulnerable to invasion by cheating, and individuals will mirror the behavior of others in a "tit-fortat" manner (I'll start by cooperating, but if you default, I will, too; see Axelrod and Hamilton 1981). When risks are high, helping behaviors are likely to occur only or primarily among kin. Humans can cooperate through extensively developed reciprocity, including indirect reciprocity; often there are complex sets of group-imposed rules restricting the competition of individuals (Alexander 1987, Boyd and Richerson 1986). Families, and in particular coalitions of related men, may specify and restrict women's mate choice to a degree unknown in any other organism (Flinn and Low 1986).

Many behaviors that we call in ordinary parlance "altruistic" have evolved because they were likely to benefit the inclusive fitness of those who did them - and are thus really reciprocal (and, genetically profitable). Alexander (1974) separated these behaviors in a clear fashion; it is obvious that genotypically altruistic behaviors, which benefit reproductive competitors at a reproductive cost to the doer, cannot evolve through natural selection (see review by Low and Heinen 1993). While they may. occur, they are always vulnerable to competition from genotypically selfish (lineage-enhancing) behaviors. True genotypic altruism, paying a real individual and familial cost for the sake of non-relatives, seems likely to remain rare. In the crosscultural literature, this principle suggests that, as we look closely, real sacrifice should be rare. And, of course, the relevance to resource problems should be immediately obvious. 


\section{The Contexts of Conservative Attitudes}

Elsewhere, I have predicted (Low and Heinen 1993) that several patterns should be apparent in resource use by traditional societies: [1] when using a resource [a] profits the an individual or his/her family, and [b] the technology is sufficient to accomplish the exploitation, use will be unrestrained; [2] when this condition exists in situations of high population density, real ecological damage can result. Even when resources are exclusively managed by small groups of relatives and neighbors likely to interact for long periods of time, over-exploitation is possible, especially when there is profit to continued exploitation (e.g. when external markets exist). Thus, the "ecologically noble savage" picture of our conventional wisdoms might be real, or might also arise from an accident of low population densities and insufficient technologies, might resources be used conservatively? When there is rapid and clear feedback regarding the impact on family and individual welfare (when over-exploitation carries clear individual and familial costs), we expect conservative management. Note that neither of these conditions are necessarily related to an expressed ethos of conservation and reverence. The combination of high population densities, profitability, and efficient technologies is recent; thus it is not surprising that widespread concern about a conservation ethic is more or less a twentieth-century phenomenon (e.g., Spoehr 1956, Hargrove 1988, Strong 1988, Callicott 1989).

It's important to separate accidental effects from those caused by human exploitation. Humans can cause destruction or extinction in a variety of ways. They may do so directly, as in hunting a species to extinction (e.g., moas in New Zealand). Extinction or environmental degradation most often follow deliberate exploitation when technology is sufficient, individual payoffs exist, especially if feedback on human impact is slow. Throughout most of our evolutionary history, these conditions were seldom met, although humans have apparently always modified their environment - even hunter-gatherers deliberately changed the environment by burning, for example, and there is evidence that traditional people are capable of over-hunting (Clay 1988, Bodley 1990). Typically, however, the technology was not widespread, and had principally local and limited environmental impacts (but see Lowdermilk 1953).

Human introductions of crops or domestic stock, or inadvertent plant or animal "weeds" can also cause ecological damage. Exploitation arise from individual striving, while introductions result more often from a lack of information (sometimes not only about the ecological relationships, but even the existence of the introduced species). From the Quaternary, documented extinctions have occurred as a direct result of human activity (Martin 1984). On the Hawaiian Islands, 54 per cent of endemic birds went extinct due to activities of early Polynesians (Olson and James 1984), and the same case, better-or-worse documented, can be made for most other continents or islands (Martin 1984). Diamond (1984) analyzed factors associated with 
resource destruction and human activity, including: weaponry, stock, pigs, dogs, swift predators like cats, agriculture. All of these were usually deliberately brought. Rats often accompanied humans inadvertently. Of the four prehistoric extinction waves definitely attributable to humans, three "resemble what literate Europeans have been doing on numerous oceanic islands" (Diamond 1984:852).

In Pleistocene North America, humans caused the extinction of large mammals, few small mammals, and some relatively large birds. Late Pleistocene extinctions in South America and Australia followed much the same pattern (Anderson 1984, Cassels 1984, Trotter and McCulloch 1984, Crosby 1986). Part of the pattern is attributable to weaponry and hunting, reflecting deliberate human exploitation; also important were introduced stock, predators, and plants, and unwanted commensals like rats. Other less-detailed examples suggest that these problems have existed throughout time. The abandonment of Mayan cities appears to have been related to agricultural failures (Deevey et al. 1979, Turner 1982). Ancient Sri Lankans, by forest clearing on mountainous regions, created flooding and reservoir siltation (Lowdermilk 1953).

Both technology and profit must be present, it seems, for significant impact; neither alone is sufficient. In North America, for example, Great Lakes Indian societies had sufficient technology to have great impact on beaver populations; nonetheless, these populations remained relatively stable until the Hudson's Bay Company entered the area, introducing a market economy, and made extra beaver pelts useful. A male beaver pelt, according to company records (Albany Fort, 1773), was worth a brass kettle, or twenty steel fishhooks, or two pounds of Brazilian tobacco (Newman 1989: 60). In this case, the technology was sufficient for some time without resulting over-exploitation; what was lacking was immediate advantage to continued intense hunting. Similarly, when steel axes were introduced in New Guinea, with a market available (Salisbury 1962), serious ecological degradation followed. On the other hand, among the Ye'kwana (Hames 1979), enhanced technology increased hunting efficiency, but did not increase exploitation. Game could neither be stored nor traded in a market economy; its availability did not lead to feast and famine conditions. Thus, already efficient hunters simply had more spare time. When such time is used in male-male bonding and negotiations, it may constitute "politics," and may indeed have some reproductive payoff for individuals (e.g., Hames 1979, Chagnon 1988, Low 1990a).

Plains Indians who hunted bison were highly selective in their use of meat, hides, and other by-products of the hunt (Haines 1970, Speth 1983), seeking particularly fat and fatty meat, and leaving heavy, less nutritious parts at the kill. When cliff jumps were used, they produced far more bison meat for less effort than competing technologies, but were hardly "conserving." Huge amounts of meat rotted at the base of cliffs; hunters took only the choicest meat. 
Do normative beliefs affect these patterns? Religious beliefs can be an important proximate cause of conservation - if individual or familial benefits accrue to conservation. That is, protective religious reverence for nature is likely to be more effective when kinship structures are strong and families benefit from conservative management. Religious protection can also be quite selective. For example, among the Semang, Wazor-Jahan (1981: 98) noted that while many religious taboos about resource utilization exist, generally "it appears that plants and trees with a utilitarian value are mythically depicted as destructive rather than beneficial to humans . . . subjected to a curse . . . which enables humans to exploit them for food and other kinds of economic uses."

In most hunting and gathering societies, the reproductive benefits to striving (being an excellent hunter) mean that while religious activities may surround hunting, men who are good hunters can get more wives, and men's attitudes about hunting (and various achievements) center on how hunting skill helps their social and reproductive success (e.g., Chagnon 1988). This appears to be true even in societies in which hunting rewards are shared (Hawkes 1993): men hunt in a manner that is not optimal from the point of view of caloric return, but may be from a reproductive viewpoint, as they pursue a "showoff' strategy, going for the big kills.

\section{The Contexts of Cooperation}

Many resources have the form of common-pool resources: many individuals have access; individual profit increases with use, so that individually, higher-than-sustainable use levels are rational (e.g. many fisheries). Managing such a resource sustainably requires cooperation, and some tradeoff of individual exploitation profit with benefits of group membership. Behavioral ecological theory predicts that cooperation will occur under specific conditions: first, among relatives who live together; second, among non-relatives in long-lived social species, capable of recognizing individuals and likely to have repeated interactions. Biologists, as well as social scientists, have profited from the "tit-for-tat" analytic approach (Axelrod and Hamilton 1981). In non-human species, there is accumulating evidence that only rewarded cooperation is likely to continue (Nowak and Sigmund 1993).

Here, there is convergence between disciplines: Ostrom's (1990: 91) design principles of long-enduring common-property resource groups include: clearly defined boundaries, participation by those affected, graduated sanctions, and the general properties of being usually small-scale and not highly variable in wealth of participants. These findings converge strongly with what behavioral ecologists predict about cooperation, both in non-humans and in preindustrial societies. But, from the biological perspective, genetic rewards count as well as 
proximate rewards of energy or status. Thus, we expect more importance to factors that increase reproductive competitive ability (e.g. cooperation in raids for cattle, etc.; see Low 1993a).

The general patterns of cooperation in other species and in pre-industrial societies thus include genetic relatedness and long-term reciprocal interactions (facilitated by living in small, non-stratified groups). Male-male cooperative ventures tend to center about "mating effort" status striving, warfare for women or resources to attract or buy women, etc. (Low 1990a). Female-female coalitions tend to be smaller-scale, less volatile, but with lower reward possibilities - more local, parental efforts such as cooperative food gathering. Female coalitions can be quite aggressive, as in some baboons, in which powerful matrilines cooperate to commit infanticide directed at reproductive competitors.

The sexes cooperate in parental care, although the typical pattern is for the division of labor to leave men able to spend more effort on mating, and the acquisition of subsequent wives (e.g. Betzig 1986, Hartung 1982). Thus the differing reproductive return curves (Low 1993b) are important: females pay a per capita cost in parental care, while much male effort is directed towards the acquisition of, e.g., status and wealth - which has a high fixed cost, but can be continually "re-used" in mating effort. Men are thus more likely to undertake risky, high-stakes ventures, while women's cooperation is likely to be lower-key.

Over and above these general patterns, some ecological influences seem likely. If, for example, cooperative strategies can function to reduce risk of failure (e.g. food-sharing), then we expect such strategies in environments in which risk of low food is great. Though we still do not expect indiscriminate cooperation, external extremes and uncertainties seem likely to promote some kinds of cooperation.

\section{Conservation Issues, The Commons, and Levels of Selection}

To conservationists, the most familiar "levels of selection" problem is probably that of the commons (e.g., Hardin 1968). These are resources to which all have access (and which, if destroyed, will hurt all), but which give short-term profit to individuals when used exploitatively. Typically, when unrelated individuals simultaneously have common access to resources, whether the resources are grazing lands or whale populations, they tend to exploit the resource more than is wise from community's long-term perspective, in order to gain personally.

Such problems should be rare if our conventional wisdoms were correct, and we all felt our interests were identical to those of humans as a group - if selection were most potent at the level of the group. It has been tempting to think of selection acting strongly on groups, without specifying relationships among individuals, or the impact of behaviors on individual inclusive fitness; in part because kin selection involves individuals other than direct lineal descendants, and 
reciprocity may involve completely unrelated individuals. For example, Wynne-Edwards (1962) and others hoped to find the answer to limited population fluctuations of many species in terms of group benefit. He argued that individuals behaved in ways that, while costing each individual reproductively, helped maintain the population below the carrying capacity, thus allowing the population to persist through time. Interestingly, Wynne-Edwards (1962) argued that all species except humans were group-selected, because human populations seemed not to be "regulated." He said this because even when he was writing, the conflicts between individual profit and group good were already clear. In fact, humans alone may show any evidence of group selection at all (laws, for example, are inflictions of constraint on individual behavior by coalitions of others in the group; Alexander 1987). Nonetheless, conflicts of interest are powerful (Hawkes and Charnov 19XX)

Selection cannot favor individuals who act for the benefit of a group of non-relatives at the expense of their own inclusive fitness; only behaviors which enhance reproductive success (such as behaviors which are selfish, parental, reciprocal, or help relatives and therefore enhance inclusive fitness), can evolve by natural selection. Situations in which the costs are paid by individuals other than those gaining the rewards are unstable. Yet this doesn't mean that we are simply harsh and fierce competitors, with no redeeming features. First, and importantly, helping our family and friends, common through individual-level selection, is common, because while it looks altruistic, in fact it is genotypically selfish. Sometimes, too, the group may appear to benefit as a result of the cumulative selection on individuals (e.g., Williams 1966) even though natural selection has acted on the level of the individual.

In sum, research for some decades now has produced no evidence that any organism has evolved to assist unrelated individuals while costing the doer. Altruistic behaviors, of course, can occur; it's just that because they can not spread by natural selection they will be rare. Mother Teresa, for example, is certainly altruistic by any standards - but she is a rarity. The obvious outcome to genotypic altruism (Alexander 19XX) is that the genetic altruists decline in the population, being steadily replaced by individuals who behave to their own reproductive benefit. Darwin (1859: 260) himself recognized the problem of altruism when he stated "if it could be proved that any species does something for the sole good of another species, my theory is annihilated, for such could not have evolved by natural selection."

This particular result of natural selection is absolutely key to understanding human resource use. When we urge, as in the 1970s environmental movement, that we should all pay an immediate, relatively small cost (e.g., taking shorter showers, taking the trouble to recycle materials), in the interests of gaining long-term global benefits, involving non-relatives and competitors, we are asking for behaviors that have no evolutionary precedent, and could only have arisen through group selection. The result? Countless proximate reasons why "it's too much 
trouble," why "my part won't make any difference," and burn-out from those who do undertake the short-term costs. In sum, when we have asked people to do things that cost them individually in the short term, no matter how laudable and reasonable, we see considerable defection. In part, we have made mistakes in our scenario-building. If we forecast utter doom by some date, we run the risk of people imagining it, but then finding, when the time comes, that things are bearable when that happens, the next gloomy scenario is less potent. And all of this complicates the fact that making things "bearable" may involve real short-term exploitation, combined with externalization of costs, and this can't be done forever.

\section{Materials and Methods}

The sample comprised the 186 societies of the Standard Cross-Cultural Sample (Murdock and White 1969), which is stratified for geographic distribution and language group, and for which available ethnographies are by qualified ethnographers resident with the society for a substantial period of time.

Independent variables. Data were coded from the Ethnographic Atlas (Murdock 1967), Atlas of World Cultures (Murdock 1981), and Murdock and Wilson (1972) for density, group size, mobility, marital residence, number of subsistence modes and importance of each subsistence type, type of animal husbandry, and type and intensity of agriculture. Murdock and Morrow (1970) produced codes for level of trade, degree to which food is stored, and "food condition" (variation in food availability). The codes for storage and trade were linked to "food condition," but "food condition" had in addition a subjective judgment about food abundance from unspecified environmental sources. Thus, codes reflected conditions such as "no significant storage, food remarkably constant" or "few simple techniques, food relatively constant year to year but varying seasonally." I separated these codes to allow analysis of trade separate from food availability and storage (Low 19XX).

Codes for the perceived or reported frequency of warfare, famine, and natural disasters were taken from Ember and Ember (1992). Data for inculcation of children to be trusting, honest, and generous, were taken from Barry et al. (1976). Codes from Whyte (1978) were used for the contribution of women to the subsistence base. Codes for risk of exposure to serious pathogens (diseases and parasites) were taken from Low (1988, 1990b).

Plant productivity and plant community type were coded from The Times Atlas of the World, Seventh Edition (1985). Data from World Weather Records were coded for temperature (heat extremes, cold extremes) and rainfall extremeness, temperature and rainfall range of variation, and the coefficient of variation of rain, and the predictability, constancy, and contingency of effective rainfall were measured using Low's (1979) modification of Colwell's

Low /April 20,1994 Behavioral Ecology of Trust 
procedure. Data were coded for the earliest dates and longest period of available information, involving an assumption that the period for which data are available is representative of past conditions for many societies. Variation in the length of time for which data are available does not affect the validity of the computations (Low 1978).

Dependent variables. Resource use codes were constructed, by naive coders, to reflect "expressed need" and "degree of utilization." "Expressed need" was coded as follows: 1= expressed need to take all available, or comments by the ethnographer that the use patterns had resulted'in clear damage (lower populations from hunting pressure, soil compaction, forest destruction); $2=$ simple description about techniques for resource use; $3=$ possible evidence of conservation behavior (e.g. "do not kill more than the family can use," some edible plants not taken. Some religious taboos fall here); 4= clear, long-term evidence of organized conservation behavior. "Utilization" was coded as follows: $1=$ some comment that everything was used (e.g. "very little was wasted; even the ...."); $2=$ simple description of use; $3=$ comment that some usable part was left.

One difficulty is immediately apparent: in comparing ethnographic data, what measure is useful to infer cooperativeness? No published (refereed) codes exist for cooperativeness. Here, I have chosen some previously coded societal traits that should be related to the ability to work cooperatively: the degree to which children are taught to trust, and to be generous and honest with others. The existence of trade implies some complementary heterogeneity of interests that could promote cooperation, and I have used trade as an indicator. For reasons of space, new codes are not reproduced here, but are freely available to interested scholars on request.

Non-parametric statistical tests were used. When variables were at least ordinal, and the relationship was linear, Spearman's Rho (Conover 1980) was calculated. For non-linear relationships, Kruskal-Wallis and Fisher Exact tests were used (Conover 1980). To check the distribution and strength of the association, two-way tables were used, and Chi-square and Phi were calculated. Multivariate analyses were done using logistic regression (Finney 1971).

\section{Results and Discussion}

\section{Resource Conservation Patterns}

Fifty two per cent (38/73) of the societies analyzed had some expression of the necessity to take all one could of what was available. Five and a half per cent (4/73) expressed some reason to leave untouched some resource; the remaining 31/73 (42.5\%) had no comment either way.

Ethnographers for just over nineteen per cent of the societies (14/73) commented that people made use of all parts of resources, including a number of items the ethnographers themselves found repugnant. Seven of the 73 societies used technologies that resulted in some

Low /April 20, $1994 \quad$ Behavioral Ecology of Trust 11 
material being left (e.g. cliff jumps for buffalo, which produced more meat than could be processed). Ethnographers made no comment beyond describing the process for the remaining $52 / 73(71.2 \%)$ societies.

Patterns of utilization show strong ecological correlates, but the expression of a conservation ethic does not. Thus, the more important hunting is in contribution to subsistence $(\mathrm{n}=73$, rho=-0.273, $\mathrm{p}=0.018)$, and the less a society relies on agriculture $(\mathrm{n}=73, \mathrm{rho}=0.286$, $\mathrm{p}=0.013$ ), the more ethnographers report that people use every scrap of a resource, perhaps reflecting the greater uncertainty of hunting. Patterns of expressed desire to conserve with hunting $(n=73$, rho=-0.197, $\mathrm{p}=0.095)$ and agriculture $(\mathrm{n}=73$, rho=--0.207, $\mathrm{p}=0.075)$ were only marginally significant. The more nomadic a society is, the more likely they are to encounter at least occasional food scarcity $(n=68$, rho $=-0.243, p=0.047)$, and the more likely the ethnographer is to report complete utilization $(\mathrm{n}=68, \mathrm{rho}=-0.271, \mathrm{p}=0.034)$; however, there is no pattern with conservation ethic $(\mathrm{n}=68, \mathrm{rho}=-0.046, \mathrm{p}=0.714)$. The greater the risk of starvation (Low path stress $\mathrm{XX})$, again, the more likely is every bit to be used $(\mathrm{n}=48, \mathrm{rho}=0.326, \mathrm{p}=0.025)$ - but again, there is no correlation with conservation ethic $(n=48$, rho $=-0.087, p=0.558)$. Conservation ethic similarly shows no pattern with the storage $(n=71$, rho $=0.003, p=0.981)$ or trade $(n=71$, rho $=0.055, \mathrm{p}=0.648)$ of food. Similarly, while utilization increases as plant productivity decreases $(n=71, k w=7.9$, d.f. $=2, p=0.019)$, expression of a conservation ethic does not $(n=71$, $\mathrm{kw}=0.315$, d.f. $=2, \mathrm{p}=0.855$ ). Interestingly, in light of the prediction that long-term conservation might be tied to familial profit, there is no correlation with expressed conservation ethic and pattern of cousin marriage $(n=72$, d.f. $=6, X 2=2.25, p=0.817)$ : concern does not increase with kinship closeness of preferred marriage partners.

Thus, while measures of actual use show rather obvious patterns with ecological conditions, there seems to be no clear pattern to the expression of need to conserve. Far from the conventional wisdom that it is common, in fact it is rare. Further, as noted above for the Semang, in at least some cases, it appears that constraints and taboos may sometimes be restricted to nonessential species.

\section{Cooperation: Ecological Factors and the Inculcation of Trust}

As population density increased, the degree to which children were trained to trust others decreased somewhat $(\mathrm{n}=134, \mathrm{rho}=-0.166, \mathrm{p}=0.055)$. This is hardly surprising; as the proportion of strangers, neither friends nor relatives, increases, the less fruitful trust is likely to be as a first approach. Population density, in turn, is strongly correlated with plant productivity, and nonextreme climatic conditions. Trust showed no relationship to the degree of nomadism $(\mathrm{n}=128$, d.f. $=1, \mathrm{X} 2=-0.027, \mathrm{p}=0.87$ ). Nomadic societies, however, strongly taught children to be generous 
more than expected $(\mathrm{n}=99$, d.f. $=1, \mathrm{X} 2=4.19, \mathrm{p}=0.04)$, a phenomenon perhaps related to the uncertainly of resource acquisition in nomadic life (Low 1989).

As the degree of risk of infection from serious, life-threatening pathogens increased, children were less strongly taught to trust others $(n=137$, rho $=-0.185, p=0.03)$. Here, the issue is not simply "stranger," but the risk from any individual. Pathogen stress shows a number of strong relationships with social factors (Low 1988, 1990b); it appears to change the costs and benefits of a variety of social relationships. Importantly, as the risk of infection by serious pathogens increảses, fewer men are suitable, healthy husbands, and the degree of polygyny increases (and, thus, the proportion of unmarried men, and the degree of male-male competition).

The inculcation of trust varied non-linearly with community size $(\mathrm{n}=135$, d.f. $=3, \mathrm{kw}=8.87$, $\mathrm{p}=0.03$ ). In small communities ( $<50$ people, $\mathrm{n}=19)$, in which people lived largely with extended kin groups, the intensity with which children were taught to trust was moderately high; it reached a maximum in communities of 51-200 people $(n=50)$ and 201-5000 $(n=61)$. In societies with very large communities $(n=5)$, children were not taught to trust others.

The intensity of trust inculcation showed no pattern with the importance of gathering, hunting, agriculture, or fishing in the food base. Interestingly, as animal husbandry increased in contribution to subsistence, children were taught to trust marginally less $(n=134$, rho $=-0.158$, $\mathrm{p}=0.07$ ); it is probably important that animal husbandry and frequency of internal warfare (which also is associated with low trust) are positively related $(\mathrm{n}=151, \mathrm{rho}=0.231, \mathrm{p}=0.005)$ - that is, wars are frequent over resources such as cattle, used for brideprice. Like polygyny, these indicate heightened male-male competition.

\section{Cooperation: Social Factors and the Inculcation of Trust}

A number of important ecological and social factors covary, and there may well be a chain of causality. As pathogen stress increased, the degree of polygyny increased. Children in monogamous and polyandrous societies were more frequently taught to trust others than children in polygynous societies $(n=135$, d.f. $=2, X 2=8.22, p=0.016)$. Thus, the most pathogen-stressed areas have both the highest degree of polygyny, and the lowest inculcation of trust.

Patterns of marital residence were strongly related to the intensity of trust inculcation $(\mathrm{n}=137$, d.f. $=4, \mathrm{X} 2=16.05, \mathrm{p}=0.003)$. In patrilocal societies, in which related groups of men coreside, children are less strongly taught to trust others, while in matrilocal, avunculocal, and neolocal societies they are strongly inculcated to trust more than expected.

When internal warfare occurred more frequently than every ten years, children were taught to trust others much less than in societies in which such warfare was rare $(n=109, X 2=13.9$, d.f. $=2, p=0.008$ ). No significant pattern emerged with the frequency of external warfare. These 
patterns carry over into other social behaviors. When trust inculcation is low (as in polygynous societies, or societies with frequent internal warfare), boys are trained to be more aggressive $(\mathrm{n}=117$, rho $=-0.444, \mathrm{p}<0.0001)$ and competitive $(\mathrm{n}=107$, rho $=-0.303, \mathrm{p}=0.0015)$. Societies in which trust inculcation is low are also societies likely to have theories of witchcraft as important explanations $(n=96, X 2=6.39$, d.f. $=1, p=0.014)$

The ways in which community leaders are chosen or emerge are also related to children's inculcation in trust $(n=137$, d.f. $=8, X 2=16.87, p=0.03)$. Societies in which there is hierarchical or complex community leadership tend to teach children to trust less strongly than expected, as opposed to societies with a headman or council.

The existence of trade suggests a complementary heterogeneity of needs, and perhaps the need for repeated interactions. Trade is more common when temperature and rainfall conditions vary greatly $(\mathrm{n}=82, \mathrm{rho}=0.222, \mathrm{p}=0.05)$. It decreases as the importance increases of gathering $(\mathrm{n}=180, \mathrm{rho}=-0.264, \mathrm{p}=0.0004)$, and hunting $(\mathrm{n}=180$, rho $=-0.328, \mathrm{p}=0.00001)$; it is marginally related to the importance of fishing $(n=180$, rho=-0.133, $\mathrm{p}=0.07)$ and agriculture $(\mathrm{n}=180$, $\mathrm{rho}=0.120, \mathrm{p}=0.11)$; and it increases strongly with the importance of animal husbandry $(\mathrm{n}=180$, rho $=0.424, \mathrm{p}=0.00001)$. Despite these patterns, the inculcation of trust is not at all related to the importance of trade $(n=135$, rho $=--0.014 \mathrm{p}=0.86)$, nor to any of the subsistence types.

\section{Is there an ecology of trust?}

Perhaps the strongest relationships between trust and other factors are those that reflect the most basic, broad predictions: that community size and degree of relatedness, degree of polygyny (reflecting competition among men), for example, will show relationships. And this makes sense. Physical factors, if extreme, are most likely to favor morphological or physiological, rather than social, responses (Low 1989, 1990a). Extremes in range of variation and unpredictability of variation in time or space will increase the complexity and cost of response.

Humans can respond far more complexly than other species; this is most evident in response to social factors (Low 1989). There are many subtle patterns, fitting under the general heading of direct and indirect reciprocity - cooperation. In fact, thought not reflected by any of the codes here, information sharing and turn-taking with respect to food gathering may lower the variance (lower risk of failure), and for poorer hunters, increase the average return (e.g. Kaplan and Hill 1985). Food sharing, while its primary purpose may be.survival and risk-reduction, is hardly immune from politics. Betzig and Turke (1986) and Betzig (1988) noted that on Ifaluk, where fishing catches vary widely, food trading/sharing is a major activity. Nonetheless, they found that chiefs are most likely to share with close kin, while distant relatives are likely to offer food to chiefs, perhaps attempting to cement alliances. It may well be that many societies treat 
unpredictable variables not as uncertainties about which little is known, but as risks (i.e., assigning heuristically some probability of failure).

Hawkes (1992) provides important insights into within-group cooperation and sharing of food. She examined foraging patterns if the Ache. Two important findings resulted. Hunters who were more successful received more attention from group members, and Hawkes (19XX) even found that more successful members fared better reproductively. Men often hunted in ways that look sub-optimal from standard optimal foraging perspectives - but in fact such men were pursuing a (high risk-high gain) "showoff" strategy that mat have suffered more variance in calories, but produced big hunting successes, and more sexual access.

As we continue to explore human responses to environmental constraints, this represents a rich area for research. Sometimes a chain of response is evident. For example, climatic extremes, probably through their impact on plant productivity, influence human density and mobility; these in turn correlate with pathogen, starvation and protein deficiency risks. Similarly, physical and biological factors can intensify sexual selection, and sexual selection can generate individual and social strategies. Social unpredictabilities appear much more likely than simple physical pressures to generate complex social responses, including the formation of cooperative coalitions. While direct and indirect reciprocity are important, any system of reciprocity may be vulnerable to manipulation and deception.

Finally, a caveat. What people say may not be what they do, or what all individuals do. The codes for inculcation of trust, for example, arise from ethnographers' judgments, sometimes from interviews and self-reports by the people interviewed rather than from quantitative assessments. We need better measures of cooperation in preindustrial societies.

\section{The Ecology of Cooperation in Non-Humans}

Data from other species are consistent with the current findings. Cooperative care of infants is often performed by older siblings — "helpers at the nest." This behavior is typical in species in which the required resources for successful establishment are rare or difficult to acquire: acorn woodpeckers, several ground squirrels, scrub jays, and, in periods of resource shortage, wolves and Cape hunting dogs. Thus, kinship predisposes to cooperation.

When non-relatives care for others' dependent offspring, often other issues are at stake. In elephants (Dunbar 1983), for example, subordinate females sometimes associate with the calves of dominant females, offering some protection in return for access to water holes, which dominant females control. In some primates, too, non-parents may offer inexpensive care; the literature, however, remained confused for some time, muddling nepotistic care with harassment by reproductive competitors (see Wasser 1983). 
Groups, with a superficial appearance of conjoint interests, can form in contexts not requiring cooperation; the principal such condition is the presence of rare and localized resources (e.g., a waterhole in the desert). In this case, there may be no advantage to coming together, so short-term, non-cooperative aggregations of animals are what we see. Truly cooperative coalitions occur in the following contexts, under quite specific conditions: feeding, predator avoidance, sexual selection (mate competition), and parental care and competition. Many species forage in groups, but most of these groups are not cooperative, but a matter of mutual exploitation. A group of sandpipers probing along the beach is seeking buried mollusks, whose location is not obvious, and which, when found, can't be eaten or protected from exploitation by others. So when one individual makes a "hit," others rush over and probe nearby. When the patch is exhausted, they move on. Truly cooperative foraging occurs when, for example, prey species weigh more than $1 / 3$ the weight of their vertebrate predator, and it is difficult for a single individual to make a kill (e.g. many species hunted by wolves,"Cape hunting dogs, lions), or when the prey moves in large groups (some fish predators cooperatively make the attack strikes: the first strike confuses the prey, second strikes are likely to be successful).

Two levels of group formation appear in predator avoidance as well. The first, like the mutual exploitation in feeding, is not cooperative. Prey species living in areas with little safe cover are no more conspicuous in groups than alone, but their chance of being caught, once seen, is $1 / \mathrm{n}$. Hamilton (1961) called this "selfish herd" behavior. Cooperative predator defense occurs in several primate species: several males, each unable to defend against a predator alone, will cooperate in defense. In familial-living species (some marmots, some ground squirrels), individuals cooperate in acting as "sentries."

Sex-Specific Cooperation. There are strong sex differences in cooperation in other species, and in most pre-industrial societies. In many species, cooperation among individuals is an effective strategy both to gain resources directly and to gain dominance that results in resource acquisition. Cooperation is known among males, among females, and between males and females. However, because reproductive return curves differ for different kinds of effort (Low 1990a, 1993b), there are crucial differences between males and females. It is probably true that coalitions evolved as, and may remain, reproductive strategies. Further, at least in polygynous societies, the potential reproductive gains, as well as the variance, are likely to be greater for men than for women (Low 1990a, 1993b). In most mammalian species, same-sex coalitions exist relatively briefly (Low, 1990a). In primates, however, long-term cooperation to compete is common. Individuals form coalitions of varying stability for reproductive reasons. If certain kinds of coalitions become, in their elaboration, indistinguishable from politics, then it is important to discern whether there are differences between the sexes in the coalitions formed or their outcomes. 
Cooperation between males, both relatives and non-relatives, can be important in sexual selection. Cheetah (Frame 1985) and lion (Packer 1986) males cooperate to get territories, and thus access to females. Chimpanzees (deWaal 1982, 1986) cooperate in alliances related to dominance, status, and access to females in such a complex way that deWaal called the process "chimpanzee politics." Dolphin males form coalitions - and sometimes temporary "supercoalitions" to keep other males from groups of females (Connor 1986). In this context, female coalitions are quite different: e.g., yellow baboon (Wasser 1983) and bonnet macaque (Silk and Boyd 1983) matrilines cooperate in harassing lower-status female reproductive competitors.

Struggles among males for status, territory, or harem control are often not always simple individual strife, but may involve coalitions. Thus, males may cooperate to gain territories (resource control) or dominance (direct access to matings). The context is therefore that of mating effort (Low 1990a, 1993b). Males may or may not be related, and coalitions may be temporary and fluid if they involve non-relatives. Many species of primates are regarded as "onemale" groups; however, even in those species, male coalitions in the mating context are known, although rare. In redtail and patas monkeys, several males may cooperatively invade a single male's group and mate with the females (Cords 1986). In gorillas (Fossey 1983) and gelada baboons (Dunbar 1983), a subordinate male may share breeding rights with the dominant for long periods. In most monkeys with multi-male groups, tolerant or cooperative relationships among males are nonetheless rare (Nishida and Hirawa-Hasegawa 1986); most males are simply competitors. This is particularly true for species in which males, upon adolescence, transfer groups. In this situation, males are seldom related. In male-bonded groups, in which males remain in the natal group, cooperation is more common; in red colubus monkeys, for example, only natal males are accepted into adult coalitions (Struhsaker and Leland 1986). Exceptional among the female-bonded, male-transfer species are savannah baboons and chimpanzees, in which males do form coalitions. In chimpanzees, male coalitions change over time, and show little correlation with social bonds, as measured by association (de Waal 1984, 1986). Though complexities are evident (Smuts 1985, 1986a), in primates for which studies have been done, high male dominance rank is associated with high male reproductive success (see review by Silk 1986:322), and thus male formation of coalitions in the context of achieving high rank is not surprising.

For females in most mammalian species, no relationship is evident between status and reproductive success (cf. Gouzoules et al. 1982), and female-female coalitions tend to center around parental effort. In lions, closely-related females share parental care and hunting duties (Bertram 1978). In some primates, groups of related females may cooperate to get resources useful to their offspring, and prevent others' access (Smuts 1985, 1986b), or to harass subordinate females in reproductive condition (Wasser 1983). In the species with female harassment of 
competitors, less dominant females have difficulty raising offspring successfully (Wasser 1983). However, because the variance in reproductive success is less than that of males, the impact of dominance on reproductive success for females is less marked than for males. In chimpanzees, female coalitions are quite stable, and overlap with the pattern of social bonds (de Waal 1984). In gorillas, female kin are friendlier and more tolerant than non-kin; and all coalitions involve kin against non-kin (Stewart and Harcourt 1986). In a number of species, there is evidence that females form coalitions to intervene in aggressive encounters on behalf of maternal kin far more often than on behalf of other individuals, and to incur greater risk for maternal kin (Silk 1986). The aggressive encounters may involve other females, or males (Smuts 1985, 1986b).

Nonetheless, reciprocal altruism does occur among non-related females, although it appears that reciprocity is less intense among non-relatives. Non-kin coalitions, incurring little risk for coalition members, are often directed against lower-ranking females (Wasser 1983, Chapais 1983). Coalitions among non-related females are rarer overall than coalitions involving non-related males, and the context of female cooperation, again, tends to be parental effort.

Thus, in non-human species, there are important sex differences in the formation and function of same-sex coalitions. Male coalitions seem largely to serve status (mating effort) competition; male rank and male coalitions are fluid, and non-related males may form coalitions. Female coalitions involve parental effort such as nursing (lions), foraging, and the support of particular individuals - kin and friends (primates). Female coalitions, though they may involve both kin and non-kin, appear to be more kin-biased than male coalitions. In most non-human primate species, males fight more intensely and injure each other more than do females (Smuts 1986b).

In all sexual species, there is at least a temporary male-female cooperation to produce offspring. In environments requiring the parental effort of both parents in feeding offspring, for example, males and females form lasting pair bonds, and cooperate in getting and distributing resources. Some male behavior will be directed toward guarding, or other behavior that increases the certainty of paternity. In species in which a single parent is markedly less successful than two parents in raising offspring, the male-female coalition may persist, sometimes for the lifetimes of the individuals. When it does so, monogamous breeding systems result. When either parent can raise offspring alone, desertion is likely (Trivers 1972, Beissinger 1987), and the two sexes are likely to garner resources independently, or cooperate while appearing to monitor the appropriateness of desertion (Beissinger 1987).

\section{Human Coalitions in Traditional Societies}


Bleak forecasts of over-exploitation due to individually-rational, group-destructive behaviors are common (e.g., Hardin 1968). Yet long-term human resource-use cooperation does exist, and can be a powerful force. Recent work (e.g., Ostrom 1990, Keohane 1984, Taylor and Singleton 1993, Putnam 1993, Martin 1993; see overview by Keohane, Ostrom, and McGinnis 1993) begins to delineate the conditions under which we expect more, rather than less, cooperative behavior in resource acquisition, and the conditions under which we predict longerterm (less discounting, less extractive) strategies of resource use. The problems are still complex, and exist at a variety of levels, from small communities to international.

Sex Differences. In humans, while the situation is obviously more complex, there does seem to be some pattern. Two very different conditions seem likely to lead to strong male-female bonds. In harsh environments in which a man and a woman can form effective resource coalitions, they are likely to do so, and the coalitions will follow confluence of reproductive interests (i.e., husband-wife; Flinn and Low 1986). Such male-female coalitions center around garnering resources for offspring, and are likely to be strongest in situations in which male and female interests are identical - monogamy. Brother-sister coalitions may exist in conditions in which certainty of paternity is low (cf. Alexander 1977, 1979). Male-female coalitions will be relatively weaker in polygynous situations, in which the male's reproductive interests are identical to those of all his wives and children, and overlap with the interests of any particular wife inversely with the number of wives.

Male-male coalitions are associated with status competition (Chagnon 1982, 1988), and with resources that can be more effectively obtained and protected by groups of males (war, heritable land of lasting value, some large game; Low 1993a). One of the most important contexts of male-male competition is that of warfare (Low 1993a). As expected, related men are most likely to help one another; for example, among the Yanomamö, warriors in an attacking group are significantly more closely related to each other than to their victims.

While male-male coalitions are likely to be among brothers (Flinn and Low 1986), and associated with patrilocal residence, more-or-less fluid coalitions of this sort arise among men of various relatedness, and among non-relatives in many societies. Such male-male coalitions may function outside the household, and may exert considerable power and control significant . resources. In our evolutionary past, men may have had more to gain from high-stakes politics than women. Male-male coalitions will exist in spite of conflict of reproductive interests of the men involved, and only if each member can gain sufficient resources or influence to better his position compared to operating alone. This may be why such coalitions are so fluid.

Coalitions among women, like male-female coalitions (and unlike male-male coalitions), tend to operate in the familial sphere, and are unlikely to be powerful outside the household; yet the reproductive interests of co-wives, even if sisters, can never approach the maximum degree of 
confluence that monogamous husband-wife coalitions exhibit. Female-female coalitions may arise among female relatives or co-wives, and appear to function for the exchange of information (e.g., location of good foraging spots), child care, and subsistence- related work (cf. Irons 1983). Resources garnered are used for offspring, family, and important reciprocators, and significant resource control is unlikely. These coalitions are almost never significant beyond the household boundaries; even female solidarity groups tend to be among relatives.

For a woman, the areas of potential conflict of interest over the distribution of resources seem likely to be: distribution to her relatives, distribution to her female reciprocators (related or unrelated), distribution to her husband's relatives, distribution to her husband's reciprocators, and distribution to his other wives in a polygynous situation. The use of resources for the man, the woman, and their offspring together are unlikely to be a source of conflict.

Differences in the potential reproductive returns, in the usual degree of relatedness of cooperators, and in the sphere of activity (familial, few resources vs. extra-familial or community, major resource/status acquisition) seem likely to be reflected by differences in the behavior of the individuals involved. Consider the options open, if they are dissatisfied, to the following individuals: a monogamously married woman, a polygynously married woman, a man in a coalition of other related and non-related men. For the man, options depend on his resources and his connections in other coalitions, and include: fighting for power openly within the coalition, trying to manipulate the rules so that the coalition operates to his own advantage, or leaving changing coalitions. Even though women's natal families have some importance as support, for neither of the women is changing coalitions liable to be a successful option. Within families open conflict is seldom successful (e.g., Beals 1961) for a variety of reasons, and avoidance of conflict is common (Blood 1960). A monogamousiy married woman loses the only ally whose reproductive interests are virtually identical to hers, and if she remarries must begin reconstructing the same confluence of interests (cf. Daly and Wilson 1984, 1985, 1987 on child abuse patterns). A polygynously married woman also has few options, and must operate in a coalition with a lesser confluence of reproductive interests with her husband. Such a woman may control few resources, cannot easily find a new coalition, and is unlikely to gain by open confrontation within the family. A major cause of divorce is conflict among co-wives, whose reproductive interests differ though these conflicts are less if co-wives are sisters. Further, a discarded wife cannot easily gain status and resources by a second, more desirable, marriage.

Collier and Rosaldo (1981) noted this difference in sphere of male versus female activities, and puzzled over the lack of ritual and cultural conceptualization of female roles; they suggested that "marriage organizes obligations, and . . . such obligations shape political life." Their discussion of the centrality of marriage to men's lives highlights the importance of male-male coalitions, in the community sphere, as mating effort. Male-male and female- female 
coalition differences, related to reproductive gain, are broader than the various asymmetries created by different marriage arrangements.

When do women compete directly for resources — when do women's coalitions function more like men's coalitions? There seem to be two such conditions, both more prevalent in Africa than elsewhere (Low 1992). In complex matrilineal or dual inheritance societies, a powerful woman, while not increasing her own number of children, may increase her grandchildren by passing her wealth and power to her son (e.g., historical Ashanti, Rattray 1923). Even when such systems are changed by contact with industrialized societies, traditions of women's independence and power, even though they no longer yield reproductive gains, may persist and thrive.

In sum, the sexual dimorphism in human coalitions parallels that in other species to a surprising degree, particularly in light of existing cultural diversity. Mating and parental effort have very different return curves for effort expended. Because we are mammals, much of women's reproductive (parental) investment must start all over for each child, although earlier-born children, when old enough, can help in food-gathering and child care. In contrast, much of a man's reproductive (mating) effort is expended as a fixed cost - getting power and status, which function just as effectively in obtaining a second or third mate as a first. Male-male coalitions center around the mating aspects of reproductive effort, frequently involve variously related men, and operate in the community sphere. Female- female coalitions involve sisters or unrelated co-wives, center around the parental aspects of reproductive effort, involve fewer resources, tend to be less fluid, and operate in the familial sphere.

\section{Detecting Cheaters}

All of the patterns described here are, to some degree, vulnerable to "cheating." Even parental care is potentially exploitable by non-relatives. In many species (e.g. wood ducks), females may sneak into the nests of others and lay eggs, forcing the parasitized female to provide parental care for offspring not her own. In some cases, the exploiters need not even be the same species: for example, the Kirtland's Warbler is currently endangered, and faces a serious problem in a fairly new parasitic exploitation by Cowbirds, who lay eggs for the Kirtland's Warbler to raise. If "cheating" occurs even at such crude levels, think how important the detection of cheating must be in more subtle situations.

If we have evolved to help our family (who carry identical genes) and friends (who will also help us), it follows that we might be discriminating in our help. Indeed, as we accumulate evidence, it looks less and less as if our brains are structured as computers working on logical premises. Indeed, social interactions are so important that they may color the way we think at the deepest levels. 
Consider two problems that are formally identical. Here are four cards. The rule is that any card with an "A" on the front must have a "3" on the back (if $\mathrm{P}$ then $\mathrm{Q}$ ). Which cards must you turn over to see if the rule is followed, or violated?

A $\quad$ B 3503

In the second problem, you are a bouncer in a bar. The rule is that anyone who is drinking a beer must be at least 21 years old (if $\mathrm{P}$ then $\mathrm{Q}$ ). Four people are sitting at a table: one you know to be 25 , one is drinking a beer, one is 16 , and one is drinking a coke. Whom do you ask for proof of age?

These problems are formally identical; the efficient, logical solution is: check $\mathrm{P}$ (A, or drinking beer) and not-Q (5, and under 21). There is no requirement that if not-P then not-Q (e.g. a 25-year old can drink a coke). Yet people solve the problems quite differently: about $25 \%$ of people solve the abstract problem, while almost $80 \%$ solve the problem in the context of detecting cheaters on the social rules (Cosmides 19XX).

Could it be simple familiarity, since more people know about drinking rules than about card rules? Apparently not; one can vary the familiarity of both abstract and social problems, and it makes no difference to solution rates - what always matters is whether there is a possibility for cheating the social rules. Consider another example: if Harry has paid, he must take the ticket (this if-P-then-Q is equivalent to detecting altruists: making sure that someone takes his or her benefits). Formally, this problem is identical to the others: If Harry has paid (P), then he must accepts the ticket he has paid for $(\mathrm{Q})$. When people are asked which of the four cards they would turn over

I_Paid_ Not Paid__ Has ticket___ No Ticket

they generate quite illogical "solutions." The logical solution is, again, to check "paid" (P) and "no ticket" (not-Q). Instead, a large proportion of people check to see whether "not paid" is paired with '"ticket" when the initial problem makes it clear that Harry has already paid!

Further experiments make it clear how important one's viewpoint is. Consider the problem: If an employee has worked ten years or more $(\mathrm{P})$, then the employee is entitled to a pension $(\mathrm{Q})$; if the employee has worked less than 10 years (not-P) then s/he is not entitled to a pension (not-Q). Note that in this problem, we are concerned both that $\mathrm{P}$ is paired with $\mathrm{Q}$, and that not-P is paired with not-Q (binary), in contrast to our first problems.

[ $>10$ years $\quad<10$ years Get pension $\quad$ No pension

How people solve this problem depends greatly on whether they are given the role of employer or employee. From an employer's viewpoint, a cheater is " $<10$ years, gets pension" — and this is what people told they are employers look for. On the other hand, people told they are employees look for "> 10 years, no pension." Formally, both conditions fail to meet the logical rules — yet how people solve them depends entirely on their perspective as employer or employee.

Low /April 20, 1994 Behavioral Ecology of Trust 22 
"Employers" never check to see if someone is not getting a pension, despite having worked ten years or more; and "employees" never check to see if someone having worked less than ten years is nonetheless getting a pension.

As the experiments accumulate, one thing is abundantly clear: though we clearly can learn logic, we nonetheless appear to solve problems at least initially in the context of our social history. And in that social history, we appear to have been concerned with protecting our own rights under the social rules, rather than protecting the rights of others. And even the crude patterns detected here, also suggest that self-interest, rather than group interest, has always been the crucial issue.

\section{Conclusions}

These data are clearly both very general, and somewhat preliminary. Yet several things stand out. First, people in traditional societies do not, at least to their ethnographers, express a widely-held conservation ethic. To the contrary, in most societies, people express individual need, rather than some sort of community, long-term planning. Second, while there are clear ecological correlates to actual patterns of use, there is no pattern to the expression of conservation ethic - neither peoples in extreme environments, nor people with plenty, are more apt to suggest conservation

Ecological management problems that require cooperation (e.g. common property resource use problems) are not uncommon. People in small, tight-knit (highly inter-related) communities in which monogamy, and maternal-kin biases, are present, and warfare is infrequent, more strongly teach their children to cooperate. These data are consistent with Ostrom's (1991) analysis of successful common-property resource management systems. That is, in traditional societies, individuals are still more likely to cooperate with their kin and long-term reciprocators.

It's a long jump from traditional societies to current industrial societies. But many of our conflict of interest, and difficulties in getting long-term cooperation among strangers, may make sense, set in this context. It's not that human nature has somehow changed, as we have become estranged from our ecological "roots"; rather we exist in a novel evolutionary environment, living among very large groups of strangers, and moving frequently. Further we have added new, and novel, layers of resource conflicts. In a way, it's encouraging that the data suggest that we have always operated by the same rules; perhaps new, expanded version of the same rules can still promote cooperation: information (necessary but not sufficient), inculcation, and social and economic (or status) incentives. 


\section{Literature Cited}

Alexander, R. D. 1977. Natural selection and the analysis of human sociality. y7 XX in C. E. Goulden (ed.). Changing scenes in the natural sciences: 1776-1976. Bicentennial Symposium Monograph, Phil. Acad. Nat. Sci. Special Publ. 12.

Alexander, R. D. 1979. Darwinism and human affairs. Seattle: University of Washington Press.

Alexander, R. D. 1987. The biology of moral systems. New York: Aldine De Gruyter. Alexander, R.D. 1990.

Barry, H. HI, L. Josephson, E. Lauer, and C. Marshall. 1976. Traits inculcated in childhood. 5. Cross-cultural codes. Ethnology 15: 83-114.

Beais, A. R. 1961. Cleavage and internal conflict: An example from India. Conflict Resolution $\mathrm{V}(1): 27-34$.

Beissinger, S. R. 1987. Mate desertion and reproductive effort in the Snail Kite. Animal Behaviour 35: 1504-1519.

Bertram, B. C R. 1978. Pride of Lions. New York: Scribner.

Betzig, L. L. 1986. Despotism and differential reproduction: A Darwinian view of history. New York: Aldine.

Betzig, L. 1988. Redistribution: Equity or exploitation. In Betzig, L., P. Turke, and M. Borgerhoff Mulder. Human Reproductive Behavior: A Darwinian Perspective. Cambridge Univ. Press, Cambridge.

Betzig, L. B., and Paul W. Turke. 1986. Food sharing on Ifaluk. Current Anthropology 27(4): $397-400$.

Blood, R. O. 1.960. Resolving family conflicts. Conflict Resolution IV(2):209-219.

Boyd, R., and P. J. Richerson. 1986. Culture and the Evolutionary Process. University of Chicago Press Chicago.

Cavalli-Sforza, L. L., and M. W. Feldman. 1981. Cultural transmission and evolution. Princeton: Princeton University Press.

Chagnon, N. 1982. Sociodemographic attributes of nepotism in tribal populations: Man the rulebreaker, in Kings'College Sociobiology Group (eds). Current problems in sociobiology. Cambridge: Cambridge University Press.

Chagnon, N. 1988. Life histories, blood revenge, and warfare in a tribal population. Science 239: 985-992.Chapais, 1983.

Chapais, B. 1983. Dominance, relatedness, and the structure of female relationships in rhesus monkeys, pp. XX in R. A. Hinde (ed.). Primate social relationships: an integrated approach. Oxford: Blackwell. 
Collier, J. F., and M. Rosaldo. 1981. Politics and gender in simple societies, pp. XX in S. B. Ortner, and H. Whitehead (eds.). Sexual meanings: the cultural construction of gender and sexuality. Cambridge Univ. Press, Cambridge.

Connor, R. 1986. Pseudo-reciprocity: Inversting in mutualism. Animal Behaviour 34: 1562-1566.

Conover, W. J. 1980. Practical non-paarametric statistics. 2nd ed. New York: Wiley.

Cords, Marina. 1986. Forest guenons and patas monkeys: Male-male competition in one-male groups, p. 98-11 in B. B. Smuts, D. L. Cheney, R. M. Seyfarth, R. W. Wrangham, and T. T. Struhsaker (eds.). Primate Societies. Chicago: Univ. Chicago Press.

Cosmides, L. 198XX.

Daly, M., and M. Wilson. 1984. A sociobiological analysis of human infanticide. pp. 487-502 in G. Hausfater and S. B. Hrdy (eds.) Infanticide: Comparative and Evolutionary Perspectives pp. 487-502. New York: Aldine.

Daly, M., and M. Wilson. 1985. Child abuse and other risks of not living with both parents. Ethology and Sociobiology 6: 197-210.

Daly, M., and M. Wilson. 1987. Children as homicide victims. pp 201-214 in R. J. Gelles and Jane B. Lancaster (eds.). Child Abuse and Neglect: Biosocial Dimensions pp. 201-214. New York: Aldine.

DeFries, J. C, R. P. Corley, R. C. Johnson, S. G. Vandenberg, and J. R. Wilson. 1982. Sex-bygeneration and ethnic group-by-generation interactions in the Hawaii Family Study of Cognition. Behavior Gentics 12:223-230.

Dublin, H. 1983. Cooperation and reproductive competition among female African elephants. $p$ 291-315 in S. K. Wasser, ed. Social Behavior of Female Vertebrates. New York: Academic Press.

Durham, W. H. 1991. Coevolution: Genes, Culture, and Human Diversity. Stanford: Stanford University Press.

Ember, C. R., and Melvin Ember. 1992. Resource unpredictability, mistrust, and war: A crosscultural study. Journal of Conflict Resolution 36(2):242-262.

Finney, D. J. 1971. Probit analysis, third ed. Cambridge Univ. Press, London.

Flinn, M. V., and Bobbi S. Low. 1986. Resource distribution, social competition, and mating patterns in human societies. In D. Rubenstein and R. Wrangham, editors. Ecological aspects of social evolution. Princeton: Princeton University Press.

Fossey, D. 1983. Gorillas in the Mist. Boston: Houghton Mifflin.

Frame, G. W. 1985. Cheetahs of the Serengeti. pp. 42-43 in D. MacDonald (ed.). The Encyclopedia of mammals. New York: Facts on File Publications.

Gouzoules, H., S. Gouzoules, and L. Fedigan. 1982. Behavioral dominance and reproductive success in female Japanese monkeys (Macaca fuscata). Anim. Behaviour 30: 1138-1150.

Low /April 20, 1994 Behavioral Ecology of Trust 
Grafen, A. 1991. Modelling in behavioural ecology, pp. 1-31 in J. R. Krebs and N. B. Davies (eds.). Behavioural ecology 3rd ed. London: Blackwell Scientific.

Hamilton, W. D. 1961. Geometry for the selfish herd. J. Theoret. Biology 31: 295-311.

Hamilton, W. D. 1964. The genetical evolution of social behaviour I,IL J. Theoretical Biology 7 : $1-52$.

Hardin, G. 1968. The tragedy of the commons. Science 162: 1243-1248.

Hartung, J. 1982. Polygyny and the inheritance of wealth. Current Anthropol. 23: 1-12.

Hawkes, K. 1992. Why hunter-gatherers work: XX

Heinen, J. T., and Bobbi S. Low. 1992. The behavioral ecology of of environmental conservation. Environmental Conservation 19(2): 105-116.

Humphrey, N. K. 1983. Consciousness regained: Chapters in the development of mind. Oxford: Oxford University Press.

Irons, William. 1983. Human female reproductive strategies, p. 169-213 in Samuel K. Wasser, ed. Social Behavior of Female Vertebrates, Academic Press, New York.

Kaplan, H., and K. Hill. 1985. Hunting ability and reproductive success among male Ache foragers: Preliminary results. Current Anthropology 26:131-133.

Keohane. R. 1984. After hegemony. Princeton: Princeton University Press.

Keohane, R., E. Ostrom, and M. McGinnis. 1993. Linking local and global commons: Monitoring, sanctioning, and theories of self-organization in common pool resources and international regimes. p 1-15 in R. Keohane, M. McGinnis, and E. Ostrom (eds) Proceedings of a Conference on Linking Local and Global Commons. Indiana University Workshop in Political Analysis and Theory, Bloomington IN.

Lewontin, R. C, S. Rose, and L. J. Kamin. 1984. Not in Our Genes: Biology, Ideology, and Human Nature. New York: Pantheon Books.

Low, Bobbi S. 1978. Environmental uncertainty and the parental strategies of marsupials and placentals. Amer. Naturalist 112: 197-213.

Low, Bobbi S, 1988. Pathogens and polygyny in humans, p. 115-127 in L. Betzig, M. Borgerhoff Mulder, and P. Turke (eds.) Human reproductive behavior: A Darwinian Approach. Cambridge Univ. Press, Cambridge.

Low, Bobbi S. 1989a. An evolutionary perspective on the training of children. J. Comparative Psychology 103:311-319.

Low, Bobbi S. 1989b. Human responses to environmental extremeness and uncertainty: A cross-cultural perspective, p. 229-255 in Cashdan, E. (ed.). Risk and uncertainty in tribal and peasant societies. Westview Press, Boulder.

Low, Bobbi S. 1989c. Occupational status and reproductive behavior in 19th century Sweden: Locknevi Parish. Social Biology 36: 82-101. 
Low, Bobbi S. 1990a. Sex, power, and resources: Male and female strategies of resources acquisition. International Journal of Contemporary Sociology 27: 45-71.

Low, Bobbi S. 1990b. Pathogen stress and human marriage systems. American Zoologist. 30: 325-339.

Low, Bobbi S. 1990c. Occupational status, land ownership, and reproductive behavior in 19th century Sweden: Tuna Parish. American Anthropologist. 92:115-126.

Low, Bobbi S. 1992. Sex, coalitions, and and politics in preindustrial societies. Politics and the Life Sciences 11(1): 63-80.

Low, Bobbi S. 1993a. An evolutionary perspective on war. pp. 13-56 in H. Jacobson and W. Zimmerman (eds.). Behavior, Culture, and Conflict in World Politics, Ann Arbor: U. Michigan Press.

Low, Bobbi S. 1993b. Ecological demography: A synthetic focus in eviolutionary anthropology. Evolutionary Anthropology 1(5): 177-187.

Low, Bobbi S., and Alice L. Clarke. 1991. Family patterns in 19th century: Impact of occupational status and landownership. Journal of Family History 16(2): 117-138.

Low, Bobbi S., Alice L. Clarke, and Kenneth Lockridge. 1992. Toward an ecological demography. Population Development Review 18(1): 1-31.

Low, Bobbi S., and J. T. Heinen. 1993. Population, resources, and environment: Implications of human behavioral ecology for conservation. Population and Environment 15(1): 7-41.

Lumsden, C. J., and E. O. Wilson. 1981. Genes, mind, and culture. Harvard University Press.

Martin, L. L. 1993. Common dilemmas: Research programs in common-pool resources and international cooperation, p 147-166 in R. Keohane, M. McGinnis, and E. Ostrom (eds) Proceedings of a Conference on Linking Local and Global Commons. Indiana University Workshop in Political Analysis and Theory, Bloomington IN.

Murdock, George Peter. 1967. Ethnographic Alas. Univ Pittsburgh Press, Pittsburgh.

Murdock, George Peter. 1981. Atlas of World Cultures. Univ Pittsburgh Press, Pittsburgh.

Murdock, G. P. , and Diana O. Morrow. 1970. Subsistence economy and supportive practices: Cross-cultural codes I. Ethnology 9: 302-330.

Murdock, George Peter, and D. White. 1969. Standard cross-cultural sample. Ethnology 8:329369.

Murdock, George Peter, and Suzanne Wilson. 1972. Settlement patterns and community organization: Cross-cultural codes 3. Ethnology 11:254-295.

Nishida, T. and M. Hiraiwa-Hasegawa. 1986. Chimpanzees and bonobos: Cooperative relationships among males, p. 165-178 in B. B. Smuts, D. L. Cheney, R. M. Seyfarth, R. W. Wrangham, and T. T. Struhsaker (eds.). Primate Societies. Chicago: Univ. Chicago Press. 
Nowak, and Sigmund. 1993.

Ostrom, E. 1990. Governing the Commons: The Evolution of Institutions for Collective Action. New York: Cambridge University Press.

Ostrom, E., and V. Ostrom. 1977. Public goods and public choices. In Alternatives for Delivering Public Services, ed. E. S. Savas, 7-49. Boulder, CO: Westview Press.

Packer, Craig. 1986. The ecology of sociality in felids. p. 429-451 in D. I. Rubenstein and R. W. Wrangham (eds). Ecological aspects of social evolution. Princeton: Princeton University Press.

Putnam, R. D. 1993. Democracy, development, and the civic community: Evidence from an Italian experiment. p 95-146 in R. Keohane, M. McGinnis, and E. Ostrom (eds) Proceedings of a Conference on Linking Local and Global Commons. Indiana University Workshop in Political Analysis and Theory, Bloomington IN.

Silk, Joan B. 1986. Social behavior in evolutionary perspective, p 318-329 in B. B. Smuts, D. L. Cheney, R. M. Seyfarth, R. W. Wrangham, and T. T. Strusaker (eds.). Primate Societies. Chicago: University of Chicago Press.

Silk, J. B., and R. Boyd. 1983. Cooperation, competition, and mate choice in matrilineal macaque groups, in S. Wasser (ed) Social behavior of female vertebrates. New York: Academic Press.

Smith, M. S., B. J. Kish, and C. B. Crawford. 1986. Inheritance of wealth as human kin investment. Ethology and Sociobiology 8(3): 171-182.

Smuts, Barbara Boardman. 1985. Sex and Friendship in Baboons. Aldine, New York.

Smuts, Barbara Boardman. 1986a. Sexual competition and mate choice, p 385-399 in B. B. Smuts, D. L. Cheney, R. M. Seyfarth, R. W. Wrangham, and T. T. Strusaker (eds.). Primate Societies. Chicago: University of Chicago Press.

Smuts, Barbara Boardman. 1986b. Gender, aggression, and influence. p. 400-412 in B. B. Smuts, D. L. Cheney, R. M. Seyfarth, R. W. Wrangham, and T. T. Strusaker (eds.). Primate Societies. Chicago: University of Chicago Press.

Stewart, K. J., and A. H. Harcourt. 1986. Gorillas: variation in female relationships, p. 155-164 in B. B. Smuts, D. L. Cheney, R. M. Seyfarth, R. W. Wrangham, and T. T. Strusaker, eds. Primate Societies. Chicago: University of Chicago Press.

Struhsaker, T. T., and L. Leland. 1986. Colobines: Infanticide by adult males, pp. 83098 in B. B. Smuts, D. L. Cheney, R. M. Seyfarth, R. W. Wrangham, and T. T. Struhsaker. (eds.) Primate Societies . Chicago: University of Chicago Press.

Taylor, M., and S. Singleton. 1993. The communal resource: Transaction costs and the solution of collective action problems, p 66-94 in R. Keohane, M. McGinnis, and E. Ostrom (eds) 
Proceedings of a Conference on Linking Local and Global Commons. Indiana University Workshop in Political Analysis and Theory, Bloomington IN.

Trivers, Robert. 1972. Parental investment and sexual selection. in B. Campbell, ed. Sexual Selection and the Descent of Man, Chicago: Aldine.

Waal, F. de. 1982. Chimpanzee Politics. Harper \& Row, New York.

Waal, F. de. 1984. Sex differences in the formation of coalitions among chimpanzees. Ethology and Sociobiology 5: 239-255.

Waal, F. de. 1986. The integration of dominance and social bonding in primates. Quart. Rev. Biology 61: 459-479. Wasser, S. K. 1983. Reproductive competition and cooperation among female yellow baboons, p 350-390 in S. K. Wasser, ed. Social Behavior of Female Vertebrates. New York: Academic Press.

Whyte, Martin K. 1979. The status of women in pre-industrial society. Princeton University Press, Princeton. 